\title{
MODEL DESCRIPTION OF ECOLOGICAL SUSTAINABILITY OF FARM CATTLE
}

\author{
Alexander Briukhanov ${ }^{1}$, Aleksandr Spesivtsev ${ }^{2}$, Vasiliy Spesivtsev ${ }^{1}$, Aleksandr Semyonov ${ }^{2}$ \\ ${ }^{1}$ Federal Scientific Agroengineering Centre VIM, Russia; ${ }^{2}$ Saint-Petersburg Institute for Informatics \\ and Automation of RAS, Russia \\ sznii@yandex.ru, sav2050@gmail.com,ryukuro@yandex.ru,ryukuro@yandex.ru
}

\begin{abstract}
Currently, there is an urgent need for environmental studies of agricultural production. This is especially true for cattle farms. In the situation of uncertainty of the initial information, the most convenient research method is mathematical modelling based on the fuzzy-probability approach. An algorithm for extracting and formalizing expert knowledge and experience by analytical expression is presented. In contrast to foreign studies, the joint influence of seven variables in one model is considered. At the same time, the factor space systematically represents the phenomenon under study and contains not only quantitative, but also qualitative variables. The impact of only technological factors was assessed, so economic indicators were not considered. An example of constructing a fuzzy-probability model of the environmental sustainability of a cattle farm in a seven-factor space is given. The validity of the model is confirmed by the factual data for three farms. Quantitative estimates of the degree of influence of both the variables themselves and their interactions have been obtained. It is shown that the influence of the number of head on the farm and the fields is about twice as significant as the influence of the applied technologies. A numerical experiment is carried out and illustrated on the basis of an adequate fuzzyprobability model. At the same time, it was found that with a significant increase in the number of cattle, the ecological stability of the farm decreases on the scale of the attribute from the level of "high" to "medium".
\end{abstract}

Keywords: farm cattle, environmental sustainability, modelling, fuzzy-possibility models, expert knowledge.

\section{Introduction}

The concentration of animals in a limited area has caused a number of problems on many issues, with the removal, treatment and use of manure being one of the most important problems. It is the negative environmental impact of organic matter and biogenic elements of the NPK group in the process of moving from animal to plant of particular concern [1].

The nature and variety of environmental costs arising from the intensification of agriculture and the organization of production in the crop and livestock sectors do not allow us to single out a single criterion by which it is possible to comprehensively evaluate the entire variety of environmental problems.

In conditions of such uncertainty, the main technique of researchers in assessing the ecological load on the seedling is the construction of models for various purposes, as well as explicit and implicit expert knowledge $[2 ; 3]$.

The analysis of international experience shows that work on the problem of environmental pollution with harmful emissions from agricultural production should be based on a systematic approach in solving production problems, rational use of food, energy, and minimization of nutrient losses. At the same time, despite the many created models of various levels and directions, environmental problems in the agricultural sector are far from being solved, making farmers have the final say [4].

In [5], it was noted that, despite the abundance of information from multiple sensors and the result of manual recording, this information is not used by farmers, since the time spent often outweighs the economic benefits. The concept of simulation models in agriculture [6] is also disappointing, since models almost always focus on one specific domain, which limits their effectiveness. Thus, feed consumption patterns are most valuable when combined with other models that predict animal responses to milk yield, changes in body weight, nutrient efficiency and gas emissions [7]. However, the models cannot yet be used in this capacity and, according to the authors, oblige the farmer to additionally evaluate alternative production strategies or regard them as an exercise in decision support. Innovation processes in agricultural production systems need to be facilitated by taking into account the main components - biological processes, farm management and advisory services. [8] In practice, farmers tend to expect a turnkey solution.

The Internet of the Future (FI) is seen as a mechanism by which a variety of systems and services can be easily integrated into an arbitrary domain, including agriculture [9], but this requires the adoption of a distributed intelligence methodology and multi-agent approaches [10]. 
The potential benefits of smart farming are numerous, but how this can be realized in terms of productivity, profitability and sustainability remains unclear to researchers [4].

However, the future is not so pessimistic, since at present intelligent forecasting systems and adaptation of the structure of models describing planning processes in complex technical organizational systems based on service-oriented architecture have already been developed and tested [11-13]. Such systems in combination with software products are able to put into practice many of the hopes expected from the Internet of the future.

If we consider a cattle farm as a complex object, then from the point of view of modeling it can, in a first approximation, be represented by the diagram in Fig. 1. The factor space here appears as a hierarchical tree. This means that all the methods and techniques proposed in [11-13] are quite applicable.

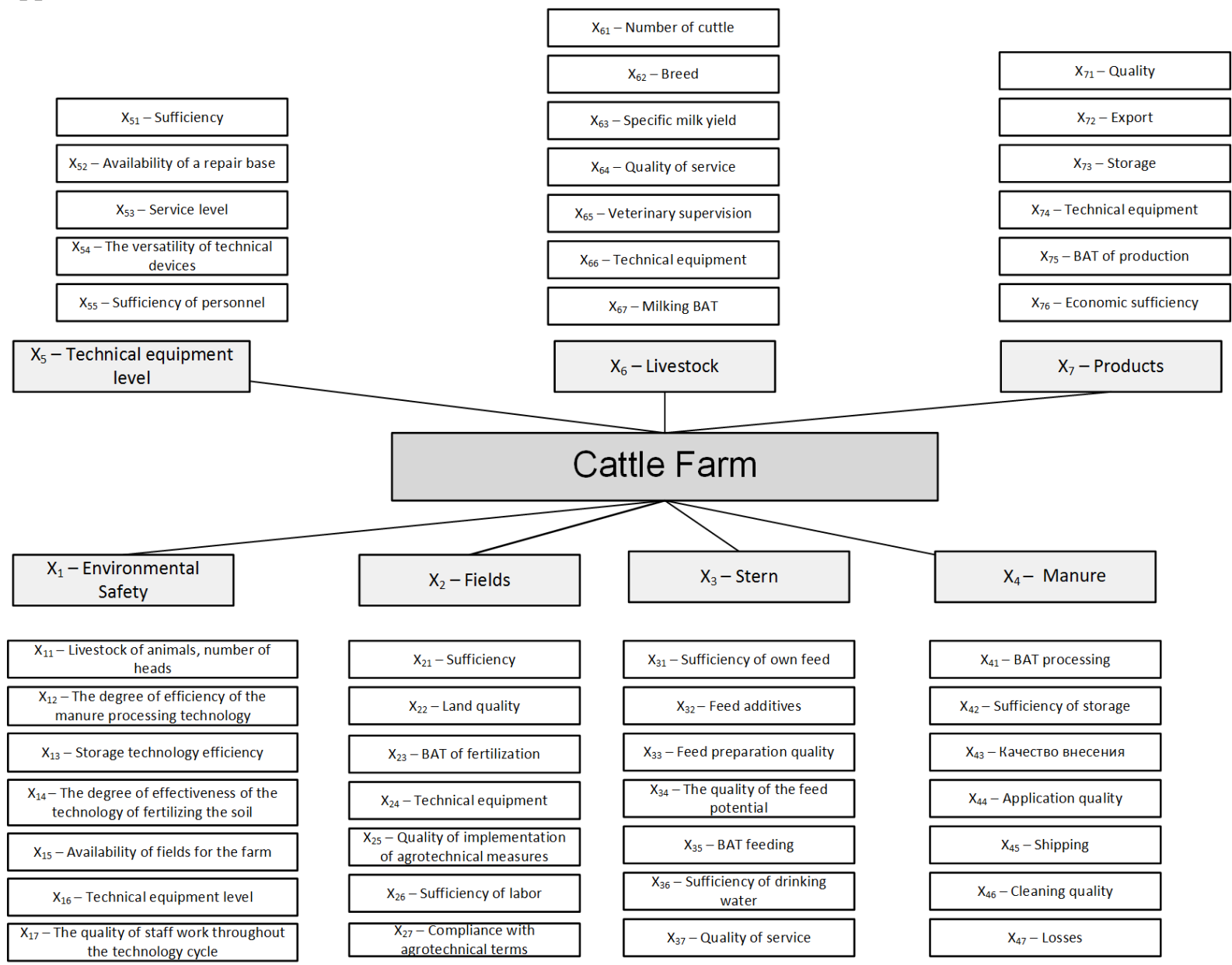

Fig. 1. Factor space diagram for modeling the state of a cattle farm

A convenient addition to the developed apparatus is a fuzzy-feasibility approach to the construction of multifactor mathematical models based on expert knowledge and experience $[1 ; 3]$, the application of which will be demonstrated by the example of studying the ecological sustainability of a cattle farm.

\section{Materials and methods}

In this study, the cattle farm is viewed as a complex system (Fig. 1), and environmental sustainability as a complex phenomenon. To study a complex phenomenon, an expert is used as an "intelligent measuring and diagnostic system" [2], from which "knowledge" is extracted. This explicit and implicit expert knowledge is the "material" to formalize in analytical expression. Such a synthesis of mathematical models implements the fuzzy-probability approach developed by the authors, which is successfully used in agriculture [1;3].

Below we will show the application of the proposed method to the construction of a fuzzypossibility model of the ecological sustainability of a cattle farm. 
The technique of a fuzzy-possibility approach to formalizing expert data with an analytical expression is as follows [2].

Step 1. Formulation of the problem, selection and substantiation of the factor space, in which the decision on the state of the $\mathrm{AO}$ is made, and the construction of verbal-numerical scales for all variables is completed.

Step 2. Presentation of the selected characteristics in the form of linguistic variables with appropriate measurement scales. Construction of a set of fuzzy production rules of the implicative type "if ... then ..." as a form of representation of expert knowledge.

Step 3. Preparation, based on the methods of the theory of planning experiments, of the survey matrix for the selected factor space and filling it out by an expert. The rows of the matrix are fuzzy production rules of the implicative type "situation - assessment". The construction of a polynomial expression is carried out by methods of the theory of planning experiments.

Step 4. The fulfilment of the requirement for the adequacy of the assessment of the AO state is checked on the basis of a comparison of the results obtained using the developed model and the results obtained by processing expert opinions.

Step 5. Conducting a professional analysis of the quality of the constructed models, extracting from the constructed adequate models by methods of mathematical analysis of new information about the specifics of the functioning of a particular SL.

According to step 1 of the methodology the experts identified the variables, the factor space of which determines the generalized state of the farm in terms of environmental safety as a whole:

- $X_{1}$ - livestock of animals, number of heads;

- $X_{2}$ - the degree of efficiency of the manure processing technology, expressing the level of nitrogen preservation as a percentage of the initial mass, $\%$ at the processing stage;

- $X_{3}$ - degree of efficiency of the storage technology, expressing the level of nitrogen preservation as a percentage of the initial mass, $\%$ at the storage stage;

- $X_{4}$ - degree of efficiency of the fertilization technology in the soil, expressing the level of nitrogen storage as a percentage of the initial mass, $\%$ at the stage of application;

- $X_{5}$ - availability of fields for the farm, $\%$ of the required;

- $X_{6}-$ level of technical equipment, $\%$ of the required;

- $X_{7}$ - quality of personnel work throughout the technology cycle, $\mathrm{b} \cdot \mathrm{r}^{-1}$;

- $Y$ - generalized indicator of the ecological sustainability of a cattle farm, $\mathrm{b} \cdot \mathrm{r}^{-1}$.

Table 1 shows the verbal characteristics of the state of the ecological sustainability of the cattle farm, according to which the descriptions are converted into numerical values.

Table 1

\section{Verbal-numerical relations when assessing the state} of ecological sustainability of a cattle farm

\begin{tabular}{|c|c|c|c|}
\hline \multirow{2}{*}{$\begin{array}{c}\text { Degree of } \\
\text { ecological safety }\end{array}$} & \multicolumn{2}{|c|}{ Modes of states } & \multirow{2}{*}{ Characteristic of state } \\
\hline & verbal & numeric & \\
\hline Low & $\mathrm{L}$ & $0.3 \mid(-1)$ & $\begin{array}{l}\text { Environmentally unsustainable cattle farm with } \\
\text { more than } 70 \% \text { environmental risk }\end{array}$ \\
\hline Below Average & BA & $0.4 \mid(-0.5)$ & $\begin{array}{l}\text { Environmentally unsustainable cattle farm with an } \\
\text { environmental risk of more than } 50 \%\end{array}$ \\
\hline Average & A & $0.5 \mid(0)$ & $\begin{array}{l}\text { Cattle farm of average environmental sustainability } \\
\text { with the risk of local incidents of harm to the } \\
\text { environment less than } 50 \%\end{array}$ \\
\hline Above Average & AA & $0.6 \mid(+0.5)$ & $\begin{array}{l}\text { Sustainable farm with minimal risks of local } \\
\text { environmental damage }\end{array}$ \\
\hline High & $\mathrm{H}$ & $0.7 \mid(+1)$ & $\begin{array}{l}\text { Environmentally sustainable farm with no } \\
\text { significant environmental risks }\end{array}$ \\
\hline
\end{tabular}


Figure 2 shows the type (step 2 of the methodology) of linguistic variables to represent the expert's knowledge of each of the factors. In practice, two scales along the abscissa axis are used for the dependent variable $\mathrm{Y}$ : verbal $\mathrm{L}, \mathrm{BA}, \ldots, \mathrm{H}$ and $0.3-0.7$ as a graphical reflection of Table 1, and for estimating the actual values of the independent variables of the factor space of the scale - verbal and standardized for the use of experimental planning methods(“-1", ,.., “ +1 ").

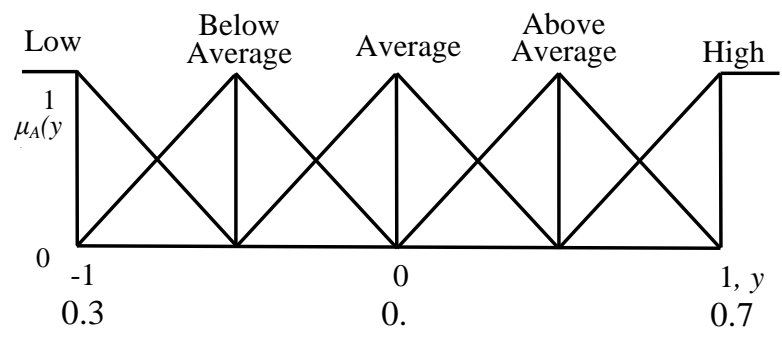

Fig. 2. General view of the linguistic variable

Further, according to step 2 of the methodology, a questionnaire matrix (Table 2) was created for an expert, where each row represents a situation (step 3) for assessing the state of the ecological sustainability of the farm, taking into account the values of the verbal-numerical Table 1 .

Fragment of the questionnaire matrix with expert estimates $Y_{E}$

Table 2 and calculated values for the model $Y$

\begin{tabular}{|c|c|c|c|c|c|c|c|c|c|c|}
\hline \multirow{2}{*}{ No. } & $(\mathbf{1})$ & $\mathbf{( 2 )}$ & $\mathbf{( 3 )}$ & $\mathbf{( 4 )}$ & $\mathbf{( 5 )}$ & $\mathbf{( 6 )}$ & $\mathbf{( 7 )}$ & \multicolumn{3}{|c|}{$(\mathbf{8})$} \\
\cline { 2 - 12 } & $x_{1}$ & $x_{2}$ & $x_{3}$ & $x_{4}$ & $x_{5}$ & $x_{6}$ & $x_{7}$ & $Y E$ & $Y E$ & $Y$ \\
\hline 1 & -1 & -1 & -1 & -1 & -1 & -1 & 1 & $\mathrm{~L}$ & 0.3 & 0.32 \\
\hline 2 & 1 & -1 & -1 & -1 & -1 & -1 & -1 & $\mathrm{BA}$ & 0.45 & 0.43 \\
\hline 3 & -1 & 1 & -1 & -1 & -1 & -1 & -1 & $\mathrm{~L}$ & 0.35 & 0.35 \\
\hline 4 & 1 & 1 & -1 & -1 & -1 & -1 & 1 & BA-A & 0.45 & 0.49 \\
\hline$\ldots$ & $\ldots$ & $\ldots$ & $\ldots$ & $\ldots$ & $\ldots$ & $\ldots$ & $\ldots$ & & $\ldots$ & $\ldots$ \\
\hline 62 & 1 & -1 & 1 & 1 & 1 & 1 & -1 & AA & 0.60 & 0.62 \\
\hline 63 & -1 & 1 & 1 & 1 & 1 & 1 & -1 & BA-A & 0.55 & 0.54 \\
\hline 64 & 1 & 1 & 1 & 1 & 1 & 1 & 1 & H & 0.70 & 0.68 \\
\hline
\end{tabular}

Note:

(1) Livestock

(2) Degree of efficiency of manure processing

(3) Degree of efficiency of storage technology

(4) Degree of efficiency of fertilization technology
(5) Sufficiency of fields for the farm

(6) Level of technical equipment

(7) Quality of personnel

(8) Generalized indicator of the ecological sustainability of a cattle farm $Y$

The processing of expert information in a quantitative form by the methods of the experiment planning theory led to the model:

$$
\begin{gathered}
Y=0.475+0.04219 x_{1}+0.01406 x_{2}+0.01719 x_{3}+0.01875 x_{4}+ \\
+0.03125 x_{5}+0.02656 x_{6}+0.02188 x_{7}+0.00625 x_{3} x_{6}+0.01719 x_{4} x_{6}+ \\
+0.00625 x_{1} x_{3} x_{4}+0.00625 x_{1} x_{3} x_{5}-0,00781 x_{3} x_{5} x_{7}
\end{gathered}
$$

where only terms with significant coefficients are presented, and variables on a standardized scale according to the formulas:

$$
x_{i}=\frac{x_{i}-\bar{x}_{i}}{\Delta x_{i}}, \bar{X}_{i}=\frac{X_{\max }+X_{\min }}{2}, \Delta X_{i}=\frac{X_{\max }-X_{\min }}{2},
$$

$i-$ number of variables.

Practical confirmation of the adequacy (step 4) of the calculations according to the model to the actual estimates $Y_{F}$ of the ecological safety of farms as a whole is shown in Table 3 . The actual state of the farms was obtained from a survey of the management representatives of cattle farms. 
The data for the entire factor space are presented in verbal form as the most convenient for evaluating by specialists. For model calculations (1), verbal estimates were converted into numerical ones according to the scales in Fig. 2 and then into a standardized form according to the formulas (2).

\section{Results of assessment for the selected factor space of the ecological sustainability of three farms}

Table 3

\begin{tabular}{|c|c|c|c|c|c|c|c|c|c|c|}
\hline $\begin{array}{c}\text { Cattle } \\
\text { farm }\end{array}$ & $\boldsymbol{X}_{1}$ & $\boldsymbol{X}_{2}$ & $\boldsymbol{X}_{3}$ & $\boldsymbol{X}_{4}$ & $\boldsymbol{X}_{5}$ & $\boldsymbol{X}_{6}$ & $\boldsymbol{X}_{7}$ & $\boldsymbol{Y}$ & $\boldsymbol{Y} \boldsymbol{e}$ & $\boldsymbol{Y}_{\boldsymbol{F}}$ \\
\hline 1 & L & BA-A & A & BA & L & AA & AA & 0.36 & L-BA & L \\
\hline 2 & AA-H & AA & AA & A-AA & H & AA & H & 0.61 & AA & AA \\
\hline 3 & A & A & BA & AA & A-AA & AA & H & 0.52 & A & L-BA \\
\hline
\end{tabular}

The presence of an adequate model (step 5 of the methodology) allows the use of mathematical analysis to obtain new information about the functioning of cattle farms. So, a numerical experiment was carried out, when the values of all variables, except one, were fixed at a certain level, and this variable changed its values along the entire scale of values of the feature from -1 to +1 , as shown in Fig. 3. By the slope of the graphs one can judge the degree of influence of the investigated factor on the dependent variable in the presence of the influence of the rest.

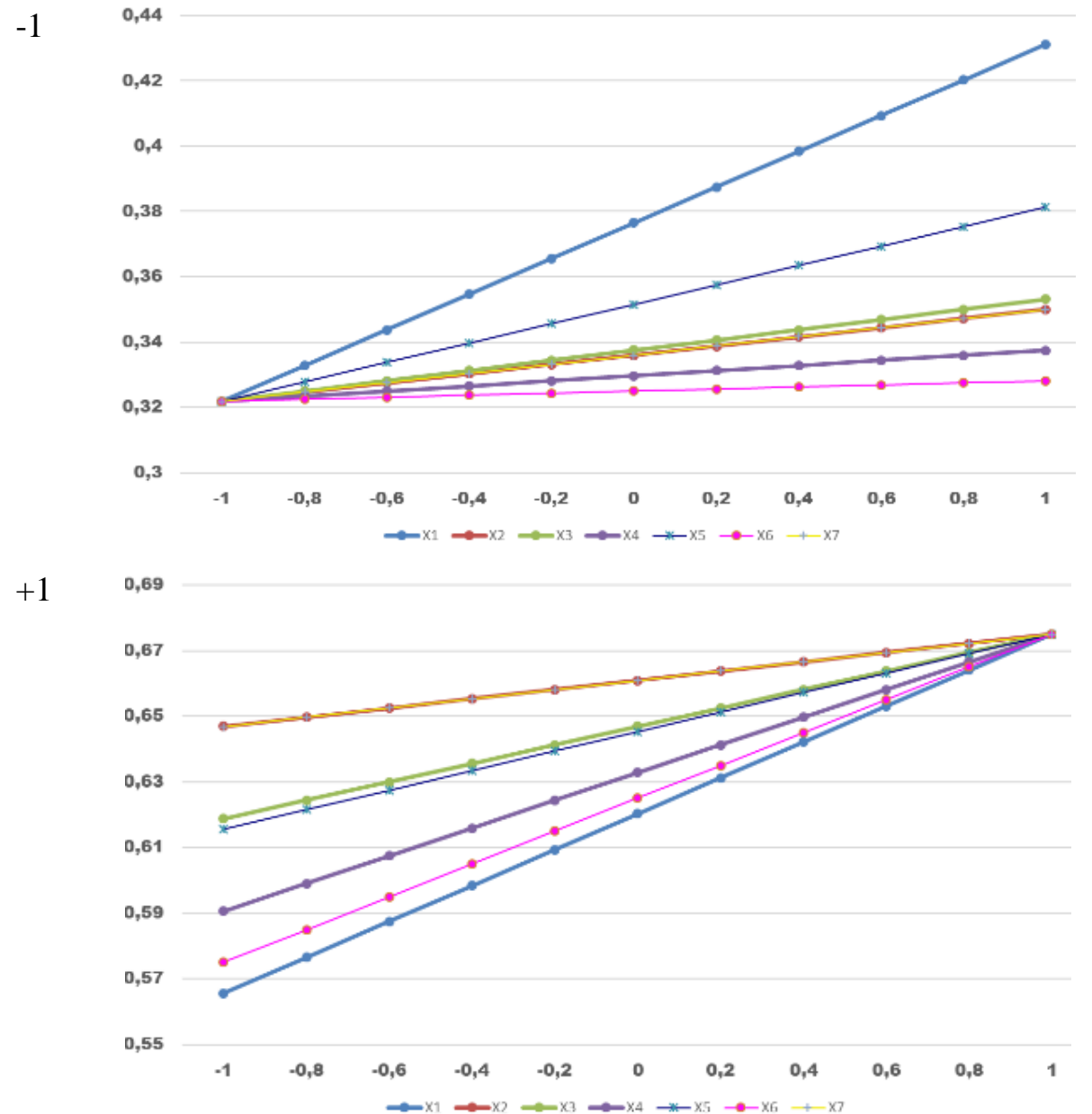

Fig. 3. Results of a numerical experiment on the estimated operating state of the farm: "-1" - the most unfavorable; "+1" - favorable

\section{Results and discussion}

The obtained analytical expression (1), which describes the phenomenon under study, is expressed as a nonlinear model. The coefficients of the model, in contrast to conventional statistical regressions, reflect the explicit and implicit knowledge of the expert. The presence of the calculation model allows 
us to assess the contribution of factors to the change in the environmental safety of the cattle farm and the relationship between the variables, the state of the ecological situation of the farm in the seven-factor space. In fact, this approach makes it possible to use the Internet of the future, the expectation of which is described in $[9 ; 10]$.

The performed numerical experiment represents two extreme states of the farm functioning: in the worst case (Fig. 3, "-1"), when all the values of the variables are at the lower levels, the ecological sustainability is assessed as "low" and even a significant decrease in the farm population $\left(x_{1}=+1\right)$ can increase the sustainability only to a value of 0,43 , which according to the scale of Table 1 corresponds to the level "below average"; in a favourable case (Fig. 3, " +1 "), when the level of environmental sustainability is "high", a significant increase in the farm livestock $\left(x_{1}=-1\right)$, with all favourable values of the variables, can reduce the sustainability from the "high" level to "medium - higher average".

Even such a brief analysis enables us to conclude that there is a certain maximum permissible livestock population, when the stability of the farm, including the ecological one, is within permissible limits. In this case, in our opinion, economic factors are critical.

\section{Conclusions}

For the first time in a seven-factor space, a mathematical model was built on the basis of systematically selected variables. The use of the fuzzy-possibility approach makes it possible to fully use the knowledge and experience of highly qualified specialists as experts. An expert in such cases is used as an "intelligent measuring and diagnostic system" in the sense that he makes "soft" measurements of the phenomenon under study and makes a diagnosis of its condition.

The numerical experiments made it possible to quantify the power of the influence of variables and their interaction on the ecological sustainability of a cattle farm.

Thus, the fundamentally understandable theoretical statements in this particular study were quantitatively assessed in practice.

\section{Acknowledgements}

The research on this topic was carried out with partial financial support within the framework of the budgetary theme No. 0073-2019-0004.

\section{References}

[1] Брюханов А.Ю., Гаас А.В. Стратегия управления отходами предприятий птицеводства на основе внедрения наилучших доступных технологий переработки помета (Waste management strategy for poultry enterprises based on the implementation of the best available technologies for processing manure). Экология и промышленность России. 2016, № 2, pp. 6063. (In Russian)

[2] Ignatiev MB, Marley E.V., Mikhailov V.V., Spesivtsev A.V. Modeling weakly formalized systems based on explicit and implicit expert knowledge - SPb: POLYTECH-PRESS, 2018, $430 \mathrm{p}$.

[3] Брюханов А.Ю., Спесивцев А.В., Субботин И.А. Моделирование негативного воздействия технологий переработки отходов животноводства (Modeling the negative impact of livestock waste processing technologies). Материалы международного конгресса «Агрорусь». 2015, pp 9-11. (In Russian)

[4] Michael J.O 'Grady, Gregory M. P.O Hare. Modelling the smart farm. Information Processing in Agriculture. Volume 4, Issue 3, September 2017, pp 179-187

[5] Pesonen L, Sørensen CAG, Nikkilä R, Rydberg A, Green O. Information and communication technology in agriculture. [online] [21.03.2021] Available at: https://www.researchgate.net/publication/252326254_NJF_Seminar_411_Information_and_Com munication_Technology_in_Agriculture.

[6] McCown R.L., Carberry P.S., Hochman Z., Dalgliesh N.P., Foale Re M.A. -inventing model-based decision support with Australian dryland farmers. 1. changing intervention concepts during 17 years of action research. crop and pasture Science, 60 (11), 2009, pp. 1017-1030

[7] Zom R.L., André G., Van Vuuren A.M. Development of a model for the prediction of feed intake by dairy cows: 1 Prediction of feed intake. Livestock Science, 143 (1), 2012, pp. 43-57. 
[8] Le Gal P.Y., Dugué P., Faure G., Novak S. How does research address the design of innovative agricultural production systems at the farm level? A Rev Agric Syst, 104 (9), 2011, pp. 714-728

[9] Lehmann R.J., Reiche R., Schiefer G. Future internet and the agri-food sector: State-of-the-art in literature and research Comp Electron Agric, 89, 2012, pp. 158-174

[10] Tynan R., O'Hare G.M.P., Marsh D., O'Kane D. Interpolation for wireless sensor network coverage Proc. EmNetS-II Proceedings of the Second IEEE Workshop on Embedded Networked Sensors. Sydney, Australia (2005), pp. 123-131

[11] Ivanov D., Sokolov B. V., Potryasaev S. A. et al. Structure Adaptation of Models Describing Scheduling Processes in Complex Technical Organizational Systems (CTOS) Proceedings 27th European Conference on Modelling and Simulation ECMS, 2013. pp. 143-148

[12] Skobtsov Y., Sekirin A., Zemlyanskaya S. Potriasaev S. et al. Application of Object-Oriented Simulation in Evolutionary Algorithms Automation Control Theory Perspectives in Intelligent Systems. Ed. by R. Silhavy, R. Senkerik, Z. K. Oplatkova et al. Advances in Intelligent Systems and Computing.Vol. 466, pp. 453-462.

[13]Zelentsov V. A., Potryasaev S. A., Pimanov I. J., Nemykin S. A. Creation of Intelligent Information Flood Forecasting Systems Based on Service Oriented Architecture. Automation Control Theory Perspectives in Intelligent Systems. Ed. by R. Silhavy, R. Senkerik, Z. K. Oplatkova et al. Advances in Intelligent Systems and Computing. Vol. 466, 2016, pp. 371-381. 